\title{
$\checkmark$ Research Square \\ Point and pixel inclusive machine learning models for exploring gully erosion susceptibility
}

\section{Swades Pal}

Professor, Department of Geography, University of Gour Banga, India.

Sandipta Debanshi ( $\nabla$ debanshi.sandipta93@gmail.com )

Research scholar, Department of Geography, University of Gour Banga, India

Satyajit Paul ( $\nabla$ spaulofficial.geo@gmail.com )

Assistant professor, Department of Geography, Gour Mahavidyalaya, India

\section{Research Article}

Keywords: Gully erosion, Mayurakshi river basin, Point and pixel based model, Ensemble machine learning

Posted Date: January 24th, 2022

DOI: https://doi.org/10.21203/rs.3.rs-1288953/v1

License: (9) This work is licensed under a Creative Commons Attribution 4.0 International License.

Read Full License 


\title{
Point and pixel inclusive machine learning models for exploring gully erosion susceptibility
}

\author{
Name- Swades Pal \\ Affiliation- Professor, Department of Geography, University of Gour Banga, India. \\ Email- swadespal2017@gmail.com \\ Name- Sandipta Debanshi** \\ Affiliation- Research scholar, Department of Geography, University of Gour Banga, India. Email- \\ debanshi.sandipta93@gmail.com \\ **Co-Corresponding author \\ Name- Satyajit Paul* \\ Affiliation- Assistant professor, Department of Geography, Gour Mahavidyalaya, India. \\ Email- spaulofficial.geo@gmail.com \\ *Corresponding author
}

\begin{abstract}
Sample point based spatial model derived from Machine Learning (ML) algorithms often generalizes the spatial pattern of event. The present study has tried to highlight how far it is acceptable and can it replace pixel based modelling? The present study has presented a comparative view of pixel and sample point based modelling of gully erosion susceptibility of the upper Mayurakshi basin to assess the predictabilities. Random forest (RF), Support Vector Machine (SVM) and (ADB) were applied for developing pixel and point based models in WEKA and Python software environments respectively. From the models, it is found that $14-25 \%$ area located mainly in the upper parts of the study unit is very highly susceptible to gully erosion. Based on the accuracy and performance level using Area under curve (AUC) of Receiver operating curve, sensitivity, precision, F1 score, MCC pixel based ensemble models are superior to point based modelling. Often, the point based models have a very poor agreement with training and testing data. So, pixel based models could not be replaced with point based models. RF is found as the best representative model. The study, therefore, recommends using pixel based modelling for this
\end{abstract}


or a similar purpose. Since the models have figured out the gully erosion susceptible areas, it would be a useful tool for related planning processes.

Keywords: Gully erosion; Mayurakshi river basin; Point and pixel based model; Ensemble machine learning

\section{Introduction}

Machine Learning (ML) algorithms based spatial models coupled with and Geographical Information System (GIS) has been used to address different issues of the wide array of disciplines including epidemiology (Auchincloss et al., 2012), climate change (Mansfield et al., 2020), natural resource (Frey, 2020), environmental vulnerability (Pal and Debanshi, 2021), environmental hazards (Wang et al., 2021) etc. Gully erosion is one of the major issues that have become a global concern with the increasing coverage of degraded land across the world (UNCCD, 2013). The global coverage of degraded land is about 30\% (Nkonya et al., 2016) and it is about 44\% in India (Mythil and Goedecke, 2016). Soil erosion by water especially in form of the gully is the most common soil degradation process (Saha et al., 2020). Gully erosion featuring deep channels eroded by running water causes that degradation locally by forming badlands over lateritic terrain (Tang et al., 2013). Gully erosion is capable of causing acute problems by causing the formation of badlands (Cánovas et al., 2017), eroding fertile soil of agricultural land (Han et al., 2018), clogging sediment in a reservoir (Dutta, 2016), depleting of groundwater table (Tilahun et al., 2016) etc. Thus, sustainable practices for soil conservation should be adopted to secure future development (Arabameri et al., 2020). The present study area, the Mayurakshi river basin, suffers from the severe problem of gully erosion due to its geo-environmental location over the degraded eastern fringe of the Chottanagpur plateau (Debanshi and Pal, 2020). Gully erosion susceptibility mapping is primarily essential for initiating such conservation practice (Debanshi and Pal, 2020). A gully erosion susceptibility mapping can be done by detecting the relationship between the existing gully occurrences and geo-environmental gully conditioning factors (Rahmati et al., 2017).

ML algorithms are becoming increasingly applied tools for assessing gully erosion and are considered robust over the traditional statistical tool for its accurate predictability (Saha et al., 2020; Arabameri et al., 2020). Several softwares and programming languages like R studio (Arabameri et al., (2018); Hosseinalizadeh et al., (2019), Waikato Environment for Knowledge 
Analysis (WEKA) (Hosseinalizadeh et al., 2019a), Python (Wang et al., 2020; Can et al., 2021) are used for implementing the ML algorithms. Several studies reported the robustness of ML models over the multi-criteria decision approach models especially when feature space is complex and the target variable is involved with the input dataset in a non-linear relationship (RodriguezGaliano et al., 2015, Churpek et al., 2016; Xie et al., 2018; Jung and Lee, 2019). ML algorithms have the potential to identify the non-linear complex relationship (Mosavi et al., 2018) and eventually produce the spatial model of gully erosion susceptibility based on associated predisposing factors of gully erosion (Saha et al., 2020). Presently the integration of remote sensing and GIS with ML and ensemble algorithms has made the mapping of any environmental issue including gully erosion easier and precise (Saha et al., 2020; Pal and Paul, 2020). For example, Arabameri et al., (2018); Hosseinalizadeh et al., (2019) used R programming language and GIS technique for assessing gully erosion susceptibility and reported greater performance accuracy and preciseness over the conventional techniques. WEKA is a software that provides a set of ML and ensemble algorithms and leverages data mining and model building (Frank et al., 2016). A good number of studies have been used the WEKA tool and GIS for developing spatial models (Hosseinalizadeh et al., 2019a; Oh et al., 2019; Pham et al., 2020). Since the software provides a set of already programmed algorithms, here the parameters can be optimized to achieve the best performance (Pal et al., 2020; Pham et al., 2020). Recently, the python programming language and associated libraries are also used for developing ML-based predictive spatial models (Wang et al., 2020; Can et al., 2021; Arbameri et al., 2021).

In this context, in recent times, the generalization of the spatial predictive model developed based on ML and Deep Learning (DL) has been in the discussion (Maxwell et al., 2016; Neyshabur et al., 2017; Kawaguchi et al., 2020; Maxwell et al., 2020; 2020a). The source of this generalization was sometimes the different geographical regions where the model was trained from and applied to (Maxwell et al., 2020) or sometimes the disparate data set (Hoeser et al., 2020; 2020a). However, in most cases, the spatial models integrated with ML algorithms and GIS limit the type of analysis that can be performed (Hogland and Anderson, 2017). The process of such model building involves multiple sequential steps viz. (1) building dataset using GIS, (2) importing the dataset in ML algorithm performing software, (3) training of the model using a set of samples of that imported dataset where the target variable is known and define a relationship between target variable and explanatory variable, (4) applying the model on the rest of the dataset, and then (5) 
producing a spatially explicit surface in GIS environment using the output of the predictive model. Producing final outputs in this manner is often challenged by multiple issues like learning of multiple software, importing and exporting of a large dataset, long processing time and requirement of larger storage space (Hogland and Anderson, 2014; 2015). While producing spatial models of a larger geographical area, these limitations become intensified especially because of the storage space related issue. Since the remote sensing datasets are becoming finer day by day, a large dataset is needed to be handled to take all the pixels of a large geographical region into account (Hogland and Anderson, 2017). Model building using a previously programmed set of algorithms like the WEKA tool suffers from such limitations a lot due to its lesser storage capacity (Naudts et al., 2004). For overcoming this issue sample point based model building is practised. This method has a fast model building benefit but often gets subjected to be generalizing or smearing the nuances of the place located further from the chosen sample sites or points. This problem reduces the precision of the mapping and eventually, the initiation of the conservation practice is compromised. This is an acute problem and could be resolved by taking all the pixels of the study area into consideration while producing any model. Python libraries give such an opportunity to handle large datasets containing all the pixels of a larger geographical region. It is an open space and the algorithms are needed to be programmed (Brownlee, 2016) therefore, becoming difficult for non-expert users. In addition, machine learning needs hyper-parameter optimization to increase the prediction accuracy which requires additional computation (Kotthoff et al., 2019). Hyper-parameters are the parameters that are set before the training process and optimization can be achieved by manual search or automatic search method (Pradhan et al., 2021). The auto-optimization function of the WEKA tool to some extend eases the hyper-parameter optimization process (Kotthoff et al., 2019) but it has limited scope and it optimizes the hyperparameters up to $70 \%$ (Brownlee, 2019). Python library enables to overcome this limitation with a broader scope of hyper-parameters optimization (Brownlee, 2016). Therefore, python libraries are considered to be superior for optimizing the hyper-parameters than WEKA (Mitrpanont et al., 2017). Here the research gap could be pointed out that whether the time and expertise expensive laborious work of pixel inclusive modelling are essential to replace the representative sample point based modelling for spatial analysis. If yes, then to what extent the precision of the pixel inclusive models is greater than the time effective and fast approach of representative sample point based modelling. Under these circumstances, the pros and cons of the spatial modelling derived from 
two different origins and environments namely sample point based modelling using WEKA tool and pixel inclusive modelling using Python libraries should be investigated. Considering this issue and for addressing the aforementioned research gap, the present study focuses on examining the better credential of ML-based Sample Point Based Modelling (SPBM) and Pixel Based Modelling (PBM) to explore gully erosion susceptibility.

\section{Study area}

The Mayurakshi river basin is located between $23^{\circ} 15^{\prime} \mathrm{N}$ to $24^{\circ} 34^{\prime} 15^{\prime \prime} \mathrm{N}$ latitude and $86^{\circ} 58^{\prime} \mathrm{E}$ to $88^{\circ} 20^{\prime} 30^{\prime \prime} \mathrm{E}$ longitude and covers more than $5403 \mathrm{~km}^{2}$ (figure $1 \mathrm{~b}$ and c). The entire basin area consists of the Rarh tract dominated by secondary lateritic formation. The rivers that originated from the Chottanagpur Plateau took part in such formation (Jha and Kapat 2003, 2009; Pal 2016).

Geologically (figure 1b) Granitic gneiss is a dominant rock type that belongs to the Pleistocene age that covers most of the upper and middle catchment of the basin. Granet-biotite gneiss is also found over a considerable area in the north-eastern part of the basin. Geomorphologically (2c), the upper and middle catchment of the basin consists of a Denudational origin pediment-pedeplain complex and in a few patches, moderately dissected hills and valleys originating from the denudational process is found. On the other hand, lower catchment mostly belongs to flood plain geomorphologically comprised by fluvial origin older alluvial plain, older flood plain and active flood plain. Geologically also this part of the basin belongs to newer and older alluvium. Eventually, this part of the basin is not subjected to severe soil erosion rather alluvial deposition by the western tributaries took part behind the formation of this part (Bandyopadhyay et al., 2014). Apart from that, the confluence part of the eastern side of the basin is merged with the Ganges delta. Almost all the gully occurrences are found in the upper and middle part of the basin geologically belongs to Granitic gneiss formation and Granet-biotite gneiss formation and geomorphologically belongs to Denudational origin pediment-pedeplain complex and Denudational origin moderately dissected hill and valleys. Therefore, these geological and geomorphological divisions have been taken as an area of interest of this study and the lower part of the basin has been excluded from the investigation (figure 1d). 



Figure 1: Geographical setup of the study area. a. location, b. geomorphological divisions, c. geological division, d. area of interest.

\section{Materials and methods}

\subsection{Materials}

For this study, 18 data layers have been prepared using various data sources like USGS Landsat images with $30 \mathrm{~m}$ spatial resolution (path/row: 139/43 and 139/44) to prepare land use land cover (LULC), Ferrous mineral index, NDVI, Bare Soil Index (BSI), and monthly fluctuation of a temperature map of the basin area. Geological has taken from Geological Survey of India whereas, BHUVAN provide the geomorphological map. Mouza wise soil texture map has been derived from National Informatics Centre (NIC). To prepare a soil erosivity map, the average monthly and annual rainfall map from the Department of Science and Technology (DST) has been used for this study. Slope, aspect, stream power index (SPI) layers have been prepared using SRTM DEMs with 
$30 \mathrm{~m}$ spatial resolution. Survey of India (SOI) toposheets of 1972 (scale 1:50,000), used to prepare river distance map, water cover area, and base map of the study area. All Landsat imageries and SRTM DEMs are pre-processed before final layer preparation.

\subsection{Software taken for PBM and SPBM}

Generally, SPBM is considered a cost-effective and quick approach for any environmental studies (Chabuk et al., 2020). Representation of the surface dynamics through these sample points minimizes the variability between two subsequent points and generates specifiable continuity in the surface (Zhu et al., 2020). PBM is another approach where all the pixels are taken into consideration for the generation of the final output (Riyadi et al., 2020). In pixel based modelling, the model has been applied on a standard dataset and the final trained model has been applied on the entire dataset or pixel (Zhu et al., 2020). There is a different platform available for sample point-based modelling (SPBM) and pixel based modelling (PBM) such as, Google Cloud ML

Engine, WEKA, Amazon Machine Learning (AML), Shogun, Apache Spark MLlib, Pytorch, Keras, TensorFlow, R-studio etc. (González et al., 2020). These platforms run various programming languages like Python, Java, $\mathrm{C}++, \mathrm{R}$ to run various machine learning algorithms. Recently, Python and $\mathrm{R}$ were used for modelling various environmental phenomena for their efficiency and big data handling capability. Whereas, software like WEKA and KNIME is used to run relatively small sample point datasets. For this study, we have used WEKA for sample point based modelling (SPBM) and python has been used for pixel based modelling (PBM).

\subsection{Selection of contributing factors for gully erosion susceptibility}

Total eighteen factors under four-factor clusters like (1) erodibility (2) erosivity (3) resistance and (4) topographical factors were taken for gully erosion susceptibility models. These factors were selected based on their importance to determine the gully erosion of the study region as well as the taking experience from the existing literature like Debanshi and Pal (2020), Saha et al. (2020). Multi co-linearity test was done to know whether there is a co-linearity problem. Variance inflation factor (VIF) statistics were computed for this. Vörösmarty and Dobos (2020) reported value of $<5$ does mean there is no co-linearity problem. The result shows that the VIF score is within permissible limits, and therefore, no significant multi co-linearity exists among selected factors (table 1). 


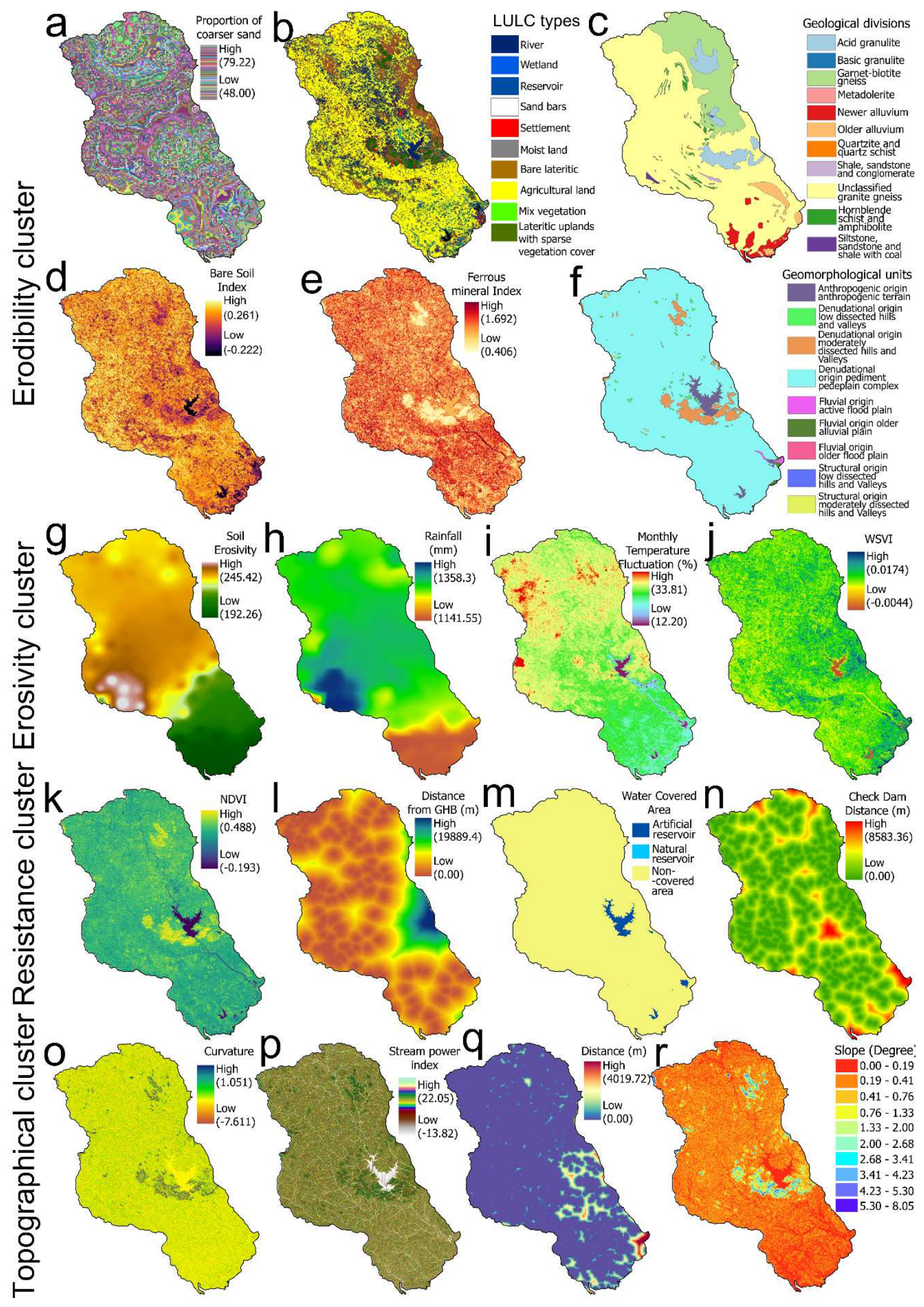


Figure 2: Raster data layers for the respective factors, (a)soli texture, (b) LULC, (c)geological aspect, (d) BSI, (e) ferrous mineral, (f) geomorphology, (g) soil erosivity, (h)monthly average rainfall, (i) monthly fluctuation of surface temperature, (j) WSVI, (k) NDVI, (l) distance from Gully headed bundh, (m) water coverage, (n) distance from check dams, (o) curvature, (p) SPI, (q) distance from first- and second-order stream, (r) slope

Table 1: VIF statistics of the gully conditioning factors.

\begin{tabular}{|c|c|c|c|c|c|c|c|c|c|c|c|c|c|c|c|c|c|c|}
\hline $\begin{array}{c}\text { Par } \\
\text { am } \\
\text { ete } \\
\text { rs }\end{array}$ & $\begin{array}{l}\mathrm{S} \\
1 \\
\mathrm{o} \\
\mathrm{p} \\
\mathrm{e}\end{array}$ & $\begin{array}{c}\mathrm{Cu} \\
\text { rva } \\
\text { tur } \\
\mathrm{e}\end{array}$ & $\begin{array}{l}\mathrm{S} \\
\mathrm{P} \\
\mathrm{I}\end{array}$ & $\begin{array}{c}\text { Di } \\
\text { sta } \\
\text { nc } \\
\mathrm{e} \\
\text { fro } \\
\text { m } \\
\text { Str } \\
\text { ea } \\
\text { m }\end{array}$ & $\begin{array}{l}\text { G } \\
\text { eo } \\
\text { lo } \\
\text { gy }\end{array}$ & $\begin{array}{c}\text { Geo } \\
\text { morp } \\
\text { holo } \\
\text { gy }\end{array}$ & $\begin{array}{c}\mathrm{S} \\
\text { oi } \\
1 \\
\mathrm{~T} \\
\mathrm{ex} \\
\text { tu } \\
\text { re }\end{array}$ & $\begin{array}{l}\text { B } \\
\text { S } \\
\text { I }\end{array}$ & $\begin{array}{c}\mathrm{Fe} \\
\mathrm{rr} \\
\mathrm{ou} \\
\mathrm{S} \\
\mathrm{co} \\
\mathrm{nt} \\
\mathrm{en} \\
\mathrm{t}\end{array}$ & $\begin{array}{l}\mathrm{L} \\
\mathrm{U} \\
\mathrm{L} \\
\mathrm{C}\end{array}$ & $\begin{array}{c}\text { Av } \\
\text { era } \\
\text { ge } \\
\mathrm{m} \\
\text { on } \\
\text { so } \\
\text { on } \\
\text { rai } \\
\text { nf } \\
\text { all }\end{array}$ & $\begin{array}{c}\text { So } \\
\text { il } \\
\text { er } \\
\text { osi } \\
\text { vit } \\
\text { y }\end{array}$ & $\begin{array}{l}\text { Mo } \\
\text { nthl } \\
\text { y } \\
\text { tem } \\
\text { per } \\
\text { atur } \\
\text { e } \\
\text { fluc } \\
\text { tuat } \\
\text { ion }\end{array}$ & $\begin{array}{l}\text { W } \\
\text { S } \\
\text { V } \\
\text { I }\end{array}$ & $\begin{array}{l}\mathrm{N} \\
\mathrm{D} \\
\mathrm{V} \\
\mathrm{I}\end{array}$ & $\begin{array}{c}\text { Di } \\
\text { sta } \\
\text { nc } \\
\text { e } \\
\text { fro } \\
\text { m } \\
\text { G } \\
\mathrm{H} \\
\mathrm{B}\end{array}$ & $\begin{array}{c}\text { Di } \\
\text { sta } \\
\text { nc } \\
\mathrm{e} \\
\text { fro } \\
\mathrm{m} \\
\mathrm{ch} \\
\mathrm{ec} \\
\mathrm{k} \\
\mathrm{da} \\
\mathrm{ms}\end{array}$ & $\begin{array}{l}\text { Su } \\
\text { rfa } \\
\text { ce } \\
\text { wa } \\
\text { ter } \\
\text { co } \\
\text { ve } \\
\text { ra } \\
\text { ge }\end{array}$ \\
\hline $\begin{array}{l}\text { VI } \\
\text { F }\end{array}$ & $\begin{array}{l}1 . \\
5 \\
4 \\
5\end{array}$ & $\begin{array}{l}1.4 \\
12\end{array}$ & $\begin{array}{l}1 . \\
4 \\
6 \\
6\end{array}$ & $\begin{array}{l}1 . \\
49 \\
0\end{array}$ & $\begin{array}{l}1 . \\
88 \\
3\end{array}$ & $\begin{array}{l}1.47 \\
5\end{array}$ & $\begin{array}{l}81 \\
9\end{array}$ & $\begin{array}{l}3 . \\
2 \\
8 \\
5\end{array}$ & $\begin{array}{l}3 . \\
45 \\
9\end{array}$ & $\begin{array}{l}1 . \\
1 \\
6 \\
9\end{array}$ & $\begin{array}{l}3 . \\
51 \\
2\end{array}$ & $\begin{array}{l}3 . \\
10 \\
4\end{array}$ & $\begin{array}{l}2.5 \\
37\end{array}$ & $\begin{array}{l}2 . \\
4 \\
1 \\
9\end{array}$ & $\begin{array}{l}3 . \\
4 \\
6 \\
0\end{array}$ & $\begin{array}{l}1 . \\
75 \\
7\end{array}$ & $\begin{array}{l}1 . \\
41 \\
6\end{array}$ & $\begin{array}{l}2 . \\
47 \\
4\end{array}$ \\
\hline
\end{tabular}

\subsection{Modelling gully erosion susceptibility}

\subsubsection{Selection of training sites for PBM and SPBM:}

For the selection of the training sites for the gully erosion susceptibility cluster modelling, the gully affected sites are considered as ' 1 ' and non-affected sites are considered as ' 0 '. Studies like Suzen and Doyuran (2004) suggested considering equal numbers of vulnerable and non-vulnerable points for better performance of the employed models. Considering this, a total of 3658 points from both the gully and non-gully erosion points out of which $80 \%$ (2926 points) data were used for modelling and 20\% (732 points) were kept for validation purposes. Since in the present study area the training sites especially the gully affected training site were limited therefore the chances of increasing the training site was also limited. In this study, we avoided unnecessary training sites from non-affected areas and used all the training sites (both gully and non-gully) as sample points for SPBM. The training sites for gully affected and non-affected points were recognized using SOI 
toposheet with 1:50,000 scale, high-resolution Google Earth imagery with $2.62 \mathrm{~m}$ spatial resolution, and field investigation.

\subsubsection{Factor cluster modelling technique:}

After selection of the sample dataset, three ML classification algorithms such as random forest (RF) AdaBoosting (ADB), and support vector machine (SVM) have been applied on the fourfactor clusters for binary classification where ' 1 ' has been considered as gully susceptible or effected points and ' 0 ' considered as non-suspectable points. The output of each cluster of sample point based modelling (SPBM) was mapped using inverse distance weighting (IDW) in an ArcGIS environment. Whereas, in PBM, the classification algorithm has been run on the entire dataset including all pixels of the study area. A detailed of mythological analysis the SPBM and PBM have been discussed below.

\subsubsection{Random forest (RF):}

In unsupervised ensemble learning, the random forest has proven to be a reliable and powerful algorithm for classification and regression (Schonlau and Zou, 2020; Meshram et al., 2021). Random forest algorithm uses bootstrap aggregation technique while growing multiple decision trees (Syam and Kaul, 2021). Therefore, each tree can predict and 'vote' independently at the time of supply of the input data for the corresponding classes $(a), \mathrm{X}_{r f}^{Y}=\operatorname{majorityvote}\left\{X_{y}(a)\right\}_{1}^{Y}$, where $X_{y} \hat{(a)}$ is the prediction of the class of the $b^{\text {th }}$ random forest (Hartini et al., 2021). The voting capability of RF reduces the noise and improves the robustness and prediction capability of the input data (Zhou et al., 2020). RF reduces the dimensionality in the database by using a built-in feature selection system that can regulate multiple parameters without removing some of them (Tella et al., 2021). By estimating the increase in prediction error in the dataset, RF can compute the variable importance scores of each constituent tree and also the entire database (Elavarasan and Vincent, 2021; Pal and Paul, 2020). Studies like Chan and Paelinckx, (2008) and Pal and Mather, (2003) reported that RF (uses bagging) is more sensitive to noise than the algorithms based on boosting technique. Finally, RF uses proximity between pairs of variables to locate the outliers (Norouzi and Moghaddam, 2020). To calculate the proximity between two samples, RF calculates 
the frequency of appearance of the sample at the same terminal node (Wangchuk and Bolch, 2020). After the computation of proximity for each pair of causes and formation of trees, the variables are normalized by dividing with numbers of trees (Nahkala et al., 2021). For the present study, a random forest algorithm from the Scikit-learn ML library from python 3.6 has been applied for PBM and the Random Forest tool from WEKA has been used for SPBM.

\subsubsection{AdaBoosting (ADB) classification:}

AdaBoosting or adaptive boosting (ADB) is a tree-based ensemble algorithm that uses an iterative process to generate weight at each sample for both classification and regression (Mehmood and Asghar, 2021; Pal and Paul, 2021). ADB consecutively grows multiple interdependent classifiers and generates multiple classifiers to 'vote' them (Xu et al., 2021). ADB generates equal weights for each dataset. In the iteration process, the weights of each unclassified dataset have been increased whereas the weight for correctly classified samples is gradually decreased (Asif et al., 2021). These weights indicate the accuracy of the classifier and it is a function of the overall weights of the correctly classified samples (Nishat et al., 2021). The accuracy of the algorithm depends on the given weight of correctly classified samples. Unlike RF, ADB is sensitive to noise in the training data therefore, it is necessary to pre-process the training data to obtain optimum output (He et al., 2020). Python-based AdaBoost Classifier from ensemble learning tool from Scikit-learn ML library used for classify factor clusters in this present study whereas, AdaBoostM1 tool in WEKA used for SPBM classification.

\subsubsection{Support vector machine (SVM):}

SVM is a popular robust supervised classification technique initially develops for binary classification problems (Cortes, and Vapnik, 1995). In this classification, several classes can be determined as an arrangement of $n$-class or $n(n-1) / 2$ or binary classification techniques by applying different selection schemes that lead to a final decision (U1 Din et al., 2021). In a given training set, SVM generates an optimum hyperplane that elucidates a complete separation of linearly distinguishable clusters in a hyper-surface (Talukdar et al., 2021). During the training, SVM searches for a hyper-plane that best separates the dataset into two classes (binary) such as 1 and 1. These instances can be identified as $h_{1}$ and $h_{-1}$ or support vectors (Deiss et al., 2020). The hyperplane between $h_{1}$ and $h_{-1}$ is referred to as a 0 or non-linear convex programming problem. 
The pairs of parameters of the separating hyperplane determination can be determined by solving the following optimization problem:

$$
\min _{w, b, \xi} \frac{1}{2} \square\left(w^{T} \cdot w\right)+C\left(\sum_{i=l}^{l} \xi_{i}\right)
$$

In respect to $1-\xi_{i}-y_{i}(w \cdot x+b) \leq 0,-\xi_{i} \leq 0, i=1, . ., \mathrm{n}$

Where penalty parameter $(\mathrm{C})$ and margin of tolerance $(\xi)$ needed to be tuned to accuracy and efficiency of the model. For this study SMOreg tool from WEKA was used for SPBM and SVC algorithm from python was used for PBM classification in python. Gridsearch $C V$ tool from the Scikit-learn ML library used for hyperparameter selection.

\subsubsection{Hyperparameter optimization:}

The selection of a proper set of hyperparameters is necessary to extract maximum performance and accuracy from the model and is considered to be an integral part of machine learning-based modelling (Kotthoff et al., 2019). Studies like Khalid et al. (2020), Victoria et al. (2020) reported that high accuracy and performance can be achieved by tuning hyperparameters. There are various techniques to tune hyperparameters like randomized search, grid search, Bayes optimization, halving grid and random search, hyper Opt-Sklearn, kNN or IBK. For this in the present study, $\mathrm{kNN}$ or IBK techniques were used to tune hyperparameter in WEKA for SPBM whereas, grid search optimization along with $K$-fold cross-validation technique was used to tune hyperparameter and validate the predicted dataset. A 10-fold iterative process for every 340 candidates totalling 2400 fits has been run for each cluster model. In python, the GridSearchCV tool from the SK-learn ML library is employed for this present work. Table 2 shows the tuned hyperparameter that came out from the optimization.

Table 2: Optimized hyper parameters for SPBM and PBM

\begin{tabular}{|c|c|c|c|c|c|c|}
\hline Models & SPBM & PBM & SPBM & PBM & SPBM & PBM \\
\hline $\begin{array}{c}\text { Cluster } \\
\text { s }\end{array}$ & \multicolumn{2}{|c|}{ RF } & \multicolumn{2}{|c|}{ ADB } & SVM \\
\hline
\end{tabular}




\begin{tabular}{|c|c|c|c|c|c|c|}
\hline 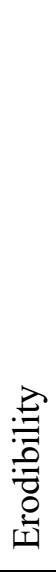 & $\begin{array}{l}\text { Max } \\
\text { depth: } 2 \text {, } \\
\text { maxi } \\
\text { features: } \\
\text { 2, min } \\
\text { samples } \\
\text { leaf: } 4 \text {, } \\
\text { min } \\
\text { samples } \\
\text { split: } 2 \text {, } \\
\text { no. of } \\
\text { estimators } \\
: 100\end{array}$ & $\begin{array}{l}\text { Max } \\
\text { depth: } 10 \text {, } \\
\text { max } \\
\text { features: } \\
3 \text {, min } \\
\text { samples } \\
\text { leaf: } 3 \text {, } \\
\text { min } \\
\text { samples } \\
\text { split: } 10 \text {, } \\
\text { no. of } \\
\text { estimators } \\
: 100\end{array}$ & $\begin{array}{l}\text { Learning } \\
\text { rate: } 0.01 \text {, } \\
\text { max depth: } \\
20 \text {, no. of } \\
\text { estimators: } \\
100 \text {, } \\
\text { Subsample } \\
: 0.2\end{array}$ & $\begin{array}{l}\text { Learning } \\
\text { rate: } 0.001 \text {, } \\
\text { max depth: } \\
80, \text { no. of } \\
\text { estimators: } \\
200 \text {, } \\
\text { Subsample } \\
: 0.5\end{array}$ & $\begin{array}{l}\text { C: } 1000 \text {, gamma: } 0.1 \text {, } \\
\text { kernel: PolyKernel, Reg } \\
\text { Optimizer:RegSMOimprove } \\
\text { d }\end{array}$ & $\begin{array}{l}\text { C: } \\
100, \\
\text { gamma } \\
: 0.1 \text {, } \\
\text { kernel: } \\
\text { rbf }\end{array}$ \\
\hline 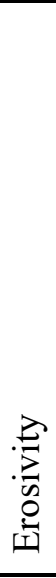 & $\begin{array}{l}\text { Max } \\
\text { depth: } 5 \text {, } \\
\text { max } \\
\text { features: } \\
\text { 4, min } \\
\text { samples } \\
\text { leaf: } 2 \text {, } \\
\text { min } \\
\text { samples } \\
\text { split: 2, } \\
\text { no. of } \\
\text { estimators } \\
: 200 \\
\end{array}$ & $\begin{array}{l}\text { Max } \\
\text { depth: } 10 \text {, } \\
\text { max } \\
\text { features: } \\
\text { 2, min } \\
\text { samples } \\
\text { leaf: } 2 \text {, } \\
\text { min } \\
\text { samples } \\
\text { split: } 9 \text {, } \\
\text { no. of } \\
\text { estimators } \\
: 300 \\
\end{array}$ & $\begin{array}{l}\text { Learning } \\
\text { rate: } 0.1 \text {, } \\
\text { maxdepth: } \\
80, \text { no. of } \\
\text { estimators: } \\
800 \text {, } \\
\text { Subsample } \\
: 0.4\end{array}$ & $\begin{array}{l}\text { Learning } \\
\text { rate: } 0.01 \text {, } \\
\text { max depth: } \\
100 \text {, no. of } \\
\text { estimators: } \\
1000 \text {, } \\
\text { Subsample } \\
: 0.7\end{array}$ & $\begin{array}{l}\text { C : 100, gamma : } 1 \text {, kernel: } \\
\text { PolyKernel, Reg Optimizer:: } \\
\text { RegSMOimproved }\end{array}$ & $\begin{array}{l}\text { C: } 10 \text {, } \\
\text { gamma } \\
: 0.1, \\
\text { kernel: } \\
\text { rbf }\end{array}$ \\
\hline 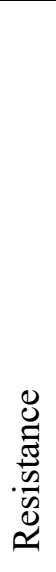 & $\begin{array}{l}\text { Max } \\
\text { depth: } 6 \text {, } \\
\text { max } \\
\text { features: } \\
\text { 3, min } \\
\text { samples } \\
\text { leaf: } 2 \text {, } \\
\text { min } \\
\text { samples } \\
\text { split: } 4 \text {, } \\
\text { no. of } \\
\text { estimators } \\
: 200\end{array}$ & $\begin{array}{l}\text { Max } \\
\text { depth: } 80 \text {, } \\
\text { max } \\
\text { features: } \\
\text { 3, min } \\
\text { samples } \\
\text { leaf: } 3 \text {, } \\
\text { min } \\
\text { samples } \\
\text { split: } 10 \text {, } \\
\text { no. of } \\
\text { estimators } \\
: 300\end{array}$ & $\begin{array}{l}\text { Learning } \\
\text { rate: } 0.001 \text {, } \\
\text { max depth: } \\
60 \text {, no. of } \\
\text { estimators: } \\
100 \text {, } \\
\text { Subsample } \\
: 0.3\end{array}$ & $\begin{array}{l}\text { Learning } \\
\text { rate: } 0.01 \text {, } \\
\text { max depth: } \\
100 \text {, no. of } \\
\text { estimators: } \\
300 \text {, } \\
\text { Subsample } \\
: 0.5\end{array}$ & $\begin{array}{l}\text { C: } 10 \text {, gamma: 0.1, kernel: } \\
\text { PolyKernel, Reg Optimizer: } \\
\text { RegSMOimproved }\end{array}$ & $\begin{array}{l}\text { C: } \\
1000, \\
\text { gamma } \\
: 1 \text {, } \\
\text { kernel: } \\
\text { rbf }\end{array}$ \\
\hline
\end{tabular}




\begin{tabular}{|c|c|c|c|c|c|c|}
\hline 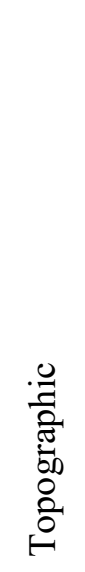 & $\begin{array}{l}\text { Max } \\
\text { depth: } 3 \text {, } \\
\text { max } \\
\text { features: } \\
2 \text {, min } \\
\text { samples } \\
\text { leaf: } 2 \text {, } \\
\text { min } \\
\text { samples } \\
\text { split: 5, } \\
\text { no. of } \\
\text { estimators } \\
: 100\end{array}$ & $\begin{array}{l}\text { Max } \\
\text { depth: } 10 \text {, } \\
\text { max } \\
\text { features: } \\
\text { 2, min } \\
\text { samples } \\
\text { leaf: } 3 \text {, } \\
\text { min } \\
\text { samples } \\
\text { split: } 8 \text {, } \\
\text { no. of } \\
\text { estimators } \\
: 200\end{array}$ & $\begin{array}{l}\text { Learning } \\
\text { rate: } \\
0.0001 \text {, } \\
\text { max depth: } \\
80, \text { no. of } \\
\text { estimators: } \\
300 \text {, } \\
\text { Subsample } \\
: 0.7\end{array}$ & $\begin{array}{l}\text { Learning } \\
\text { rate: } 0.1 \text {, } \\
\text { max depth: } \\
100 \text {, no. of } \\
\text { estimators: } \\
100 \text {, } \\
\text { Subsample } \\
: 0.5\end{array}$ & $\begin{array}{l}\text { C: 1000, gamma: 0.1, } \\
\text { kernel: PolyKernel, Reg } \\
\text { Optimizer: } \\
\text { RegSMOimproved }\end{array}$ & $\begin{array}{l}\text { C: } 10 \text {, } \\
\text { gamma } \\
: 0.001 \text {, } \\
\text { kernel: } \\
\text { rbf }\end{array}$ \\
\hline
\end{tabular}

\subsection{Accuracy assessment of the PBM and SPBM:}

To affirm the performance of the employed models, six statistical matrices namely percentage of correctly classified data, receiver operating characteristics (ROC) of the area under the curve (AUC), Precision, Sensitivity, F1-score, and Matthew's correlation coefficient (MCC) has been calculated based on 1098 sample points. The validation techniques are calculated based on four matrices such as true positive, false negative, true negative, and false positive. The ROC (AUC) or AUROC is calculated against the true and false positive sites of the predicted dataset (Naghibi et al., 2020). Insensitivity and precision are the true positive, false negative and false positive values of the predicted data used for calculation whereas, in MCC all four matrices have been used for better reliability and performance (Chicco et al., 2021). The MCC value ranges from -1 to 1, where -1 indicates the least accuracy in the prediction and vice-versa. The F1-score was calculated against the value of precision and sensitivity. Therefore, it gives a bit better result which is even better in uneven class distribution (Chicco and Jurman, 2020). The value of ROC-AUC, Precision, and F1-score, ranges between $0-1$, where absolute 0 or near to 0 indicates less reliability on the model and 1 indicates maximum reliability on the employed models (Yao and Shepperd, 2020). All four matrices have some superiority and flaws against another one therefore, a score of any single model cannot be taken as a good indicator for model validation. The calculation for the stated matrices are as follows:

$$
\text { recall }=\text { sensitivity }=\frac{T p}{T p+F n} \ldots \mathbf{E q} \cdot \mathbf{1}
$$




$$
\text { precision }=\frac{T p}{(T p+F p)} \ldots \mathbf{E q} \cdot \mathbf{2}
$$

$M C C=\frac{T p \times T n-F p \times F n}{\sqrt{(T p+F p)(T p+F n)(T n+F p)(T n+F n)}} \ldots . \mathbf{E q} \cdot \mathbf{3}$

$$
F 1-\text { score }=\frac{\text { precision } \times \text { recall }}{\text { precision }+ \text { recall }} \ldots \mathbf{E q .} 4
$$

\section{Results}

\subsection{Gully erosion susceptible models PBM and SPBM}

Figure 3 displays the comparative views of pixels and sample points based on ensemble ML models for gully erosion susceptibility in the upper Mayurakshi river basin. Each map was classified into five gully erosion susceptible zones and the area under each class is shown in table 3. About $15-20 \%$ of the area was detected as a very highly susceptible gully erosion zone as per pixel based ML models. On the other hand, this ranges from 1-26\% in case of sample point based ML models. From these statistics, it can be stated that sample point based modelling reflected a greater degree of prediction uncertainty. The gap between pixel and point based very highly susceptible area was found very high in case of the ADB model and found low in case of RF model. Such inconsistency in prediction is caused for the question of reliability of sample point based models. Geographically, the upper parts of the study region are high to very highly susceptible to gully erosion. Highly erodible coarse-textured laterite soil, relatively sloppy Chottanagpur plateau fringe, highly dense $1^{\text {st }}$ and $2^{\text {nd }}$ orders streams are mainly responsible for such greater gully erosion susceptibility (Pal, 2016; Pal and Debanshi, 2018; Debanshi and Pal, 2020). Areal patches of very highly erosion susceptibility are looking quite continuous in case of point-based modelling and this geolocation is deliberately different from pixel based ML model output. So, justification of suitability of the model's application for such work is very essential. Moreover, it is also essential to justify the suitability of the pixel and point based ML models. For that accuracy, a test is highly essential.

Table 4 shows the accuracy and performance level of the applied models with the help of some statistical techniques like AUC-ROC, precision, sensitivity, F1 score and MCC. In case of sample point based ML models, AUC and MCC range from 0.53-0.74 and 0.48-0.69 whereas it ranges 
from 0.81-0.91 and 0.78-0.91 respectively in case of pixel based ML models. Sensitivity, precision and F1 score also represent the same trend (Table 4). Based on these statistics, it could be inferred that pixel based gully erosion susceptible models are more superior than sample point based models. Obviously, in case of sample point based models, the sample size may influence the accuracy level, however, at any sample size it will not be as precise as the pixel based models. Among the tree applied ensemble ML models, RF was found to be the best representative since the accuracy level as per all the test statistics was high both in pixel and point based models. AUCROC value shows a very good to excellent agreement between training and test data set in case of all the models applied for predicting pixel based susceptibility, however, RF was recognized as the best suited. The agreement between test and training dataset was unacceptable to fairly good in case of point based ML models.

Thirty-seven field data regarding extension of the gully, widening and deepening of the gully were collected for validating the ML gully erosion susceptible models. Gully erosion rate was correlated with the degree of gully erosion susceptibility. Correlation coefficients between the degree of susceptibility and headward extension of gully, gully widening and deepening were respectively0.65-0.77, 0.58-0.62 and 0.73-0.81 respectively in case of pixel based models and all these values are statistically significant at 0.05 to 0.1 level of significance. Highest correlation was found in case of the RF model. In case of sample point based ML models, correlation coefficient values range from $0.12-0.35,0.13-0.29$ and $0.17-0.34$ and the significance level is $<0.05$. 


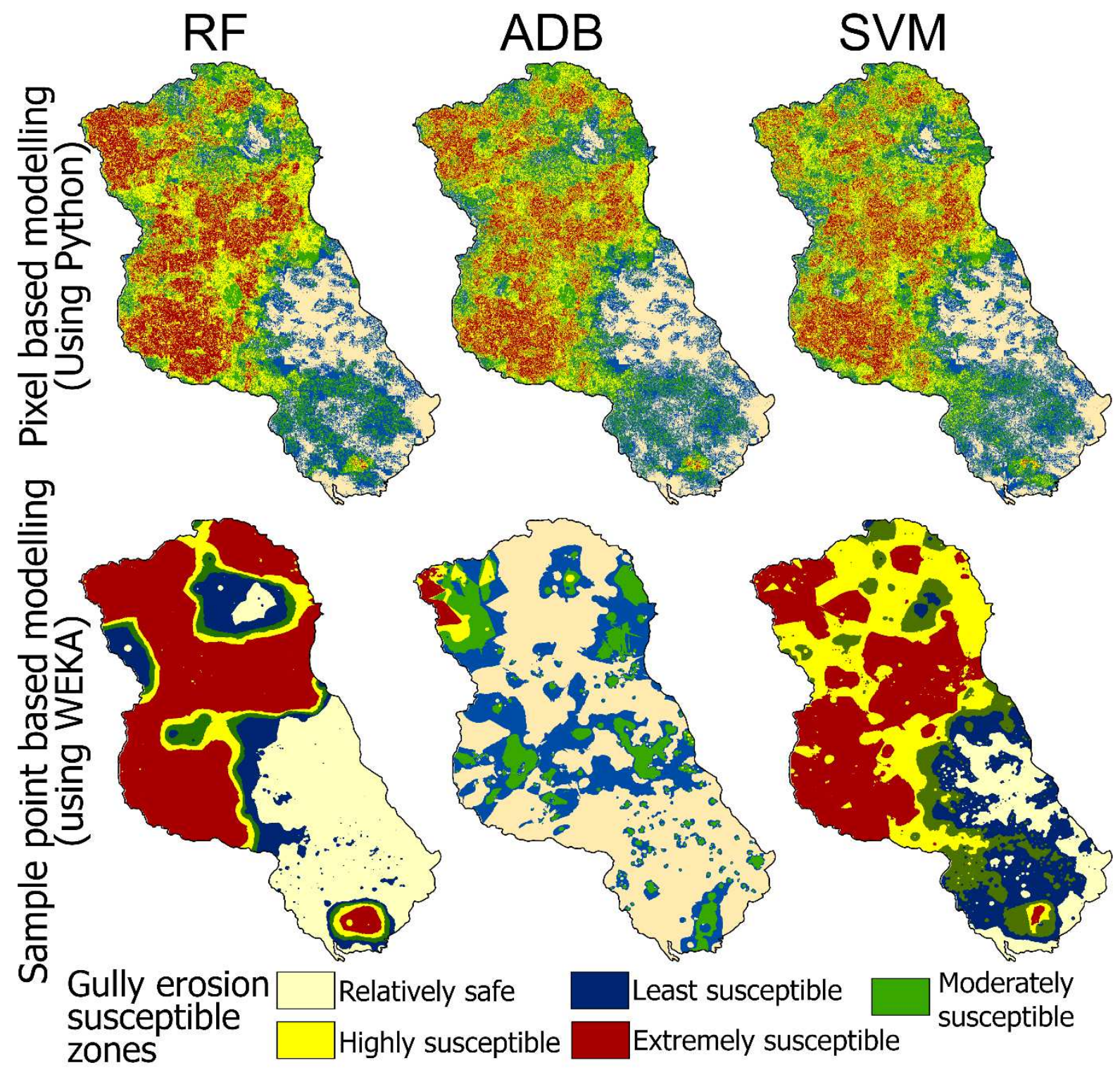

Figure 3: Gully erosion susceptible zones derived from python and WEKA

Table 3: Percentage of the area under different gully erosion susceptible zones based on python and WEKA (PBM: Pixel based modelling; SPBM: Sample point based modelling)

\begin{tabular}{|l|l|c|c|c|l|c|}
\hline Models & \multicolumn{2}{|c|}{ RF } & \multicolumn{2}{c|}{ ADB } & \multicolumn{2}{c|}{ SVM } \\
\hline Modelling software & $\begin{array}{c}\text { PBM } \\
\text { (Python) }\end{array}$ & $\begin{array}{c}\text { SPBM } \\
\text { (WEKA) }\end{array}$ & $\begin{array}{c}\text { PBM } \\
\text { (Python) }\end{array}$ & $\begin{array}{c}\text { SPBM } \\
\text { (WEKA) }\end{array}$ & $\begin{array}{c}\text { PBM } \\
\text { (Python) }\end{array}$ & $\begin{array}{c}\text { SPBM } \\
\text { (WEKA) }\end{array}$ \\
\hline $\begin{array}{l}\text { Gully erosion } \\
\text { susceptibility zones }\end{array}$ & $\begin{array}{l}\text { total } \\
\text { area }\end{array}$ & $\begin{array}{l}\text { \% to total } \\
\text { area }\end{array}$ & $\begin{array}{l}\text { total } \\
\text { area }\end{array}$ & $\begin{array}{l}\text { \% to total } \\
\text { area }\end{array}$ & $\begin{array}{l}\text { total } \\
\text { area }\end{array}$ & $\begin{array}{l}\text { \% to total } \\
\text { area }\end{array}$ \\
\hline Relatively Safe & 16.62 & 31.86 & 18.63 & 58.26 & 16.06 & 11.04 \\
\hline Less susceptible & 18.04 & 11.53 & 18.30 & 26.79 & 19.13 & 16.35 \\
\hline
\end{tabular}




\begin{tabular}{|l|r|r|r|r|r|r|} 
Moderate susceptible & 19.55 & 5.84 & 19.74 & 12.26 & 23.37 & 23.85 \\
\hline High susceptible & 25.64 & 25.23 & 25.68 & 1.56 & 26.84 & 26.85 \\
\hline Very High susceptible & 20.14 & 25.55 & 17.65 & 1.13 & 14.60 & 21.92 \\
\hline
\end{tabular}

Table 4: Statistical accuracy SPBM and SPBM

\begin{tabular}{|c|c|c|c|c|c|c|c|c|}
\hline $\begin{array}{c}\text { Classifier } \\
\text { s }\end{array}$ & $\begin{array}{l}\text { Modelling } \\
\text { software }\end{array}$ & $\begin{array}{c}\text { Correctl } \\
\text { y } \\
\text { classifie } \\
\text { d }(\%)\end{array}$ & $\begin{array}{l}\text { ROC } \\
(\mathrm{AUC} \\
\quad)\end{array}$ & $\begin{array}{c}\text { Precisio } \\
n\end{array}$ & $\begin{array}{c}\text { Sensitivit } \\
\mathrm{y}\end{array}$ & $\begin{array}{c}\text { F1- } \\
\text { score }\end{array}$ & $\begin{array}{c}\mathrm{MC} \\
\mathrm{C}\end{array}$ & $\begin{array}{c}\text { Suppor } \\
\mathrm{t}\end{array}$ \\
\hline \multirow{2}{*}{$\mathrm{RF}$} & $\begin{array}{c}\text { PBM } \\
\text { (Python) }\end{array}$ & 97.25 & 0.91 & 0.941 & 0.921 & 0.931 & $\begin{array}{c}0.91 \\
2\end{array}$ & 1098 \\
\hline & $\begin{array}{c}\text { SPBM } \\
\text { (WEKA) }\end{array}$ & 72.03 & 0.743 & 0.715 & 0.701 & 0.708 & $\begin{array}{c}0.69 \\
2\end{array}$ & 1098 \\
\hline \multirow{2}{*}{$\mathrm{ADB}$} & $\begin{array}{c}\text { PBM } \\
\text { (Python) }\end{array}$ & 93.23 & 0.862 & 0.884 & 0.908 & 0.896 & $\begin{array}{c}0.90 \\
3\end{array}$ & 1098 \\
\hline & $\begin{array}{c}\text { SPBM } \\
\text { (WEKA) }\end{array}$ & 53.69 & 0.531 & 0.512 & 0.49 & 0.501 & $\begin{array}{c}0.48 \\
7\end{array}$ & 1098 \\
\hline \multirow{2}{*}{ SVM } & $\begin{array}{c}\text { PBM } \\
\text { (Python) }\end{array}$ & 91.01 & 0.81 & 0.781 & 0.792 & 0.786 & $\begin{array}{c}0.77 \\
9\end{array}$ & 1098 \\
\hline & $\begin{array}{c}\text { SPBM } \\
\text { (WEKA) }\end{array}$ & 67.11 & 0.638 & 0.631 & 0.662 & 0.646 & $\begin{array}{c}0.62 \\
4\end{array}$ & 1098 \\
\hline
\end{tabular}

\subsection{Factor cluster based models}






Figure 4: (1) pixel based and (2) sample point based factor cluster model

Figure 4 displays the comparative views of pixel and point based gully erosion susceptibility modelling of four-factor clusters like (1) erodobility (2) erosivity (3) resistance and (4) topographical factor cluster. Based on the considered factors under each factor cluster, the nature of susceptible areas were determined. Point based models show continuous patches of susceptible areas whereas its areal extension is highly fragmented. All the factor clusters based model has recognized wide parts of the upper catchment area under gully erosion susceptibility. This proportion is susceptible high in case of topographical factor cluster. Both pixel and point based factor cluster models have recognized upper parts of the study region is under soil erosion 
susceptibility, however, in terms of geolocation, these are not coinciding always. So, it is necessary to justify whether pixel based model is superior to sample point based model. Here one thing is clear that if factor cluster based model is validated with testing data set, in most of the cases it may show relatively poor agreement. However, considering the relative difference of statistical values of the applied measures, it could be easy to infer the suitability of the models. Table 5 depicts the validation and model performance statistics of each factor cluster model. From the table, it is very evident that AUC, MCC, Precision, sensitivity and F1 scores are significantly higher in case of pixel based model $(>0.7)$ than sample point based model $(<0.5)$. In case of sample point based models, these values show the unacceptable agreement between training and testing datasets. Here also RF model has appeared the best suited than other models.

Table 5: Cluster wise comparative state of statistical accuracy between pixel and point based modelling (statistics based on susceptible zones only)

\begin{tabular}{|c|c|c|c|c|c|c|c|c|c|}
\hline $\begin{array}{c}\text { Mod } \\
\text { els }\end{array}$ & Clusters & $\begin{array}{l}\text { Modelling } \\
\text { software }\end{array}$ & $\begin{array}{c}\text { Correct } \\
\text { ly } \\
\text { classifi } \\
\text { ed }(\%)\end{array}$ & $\begin{array}{l}\text { ROC } \\
\text { (AUC) }\end{array}$ & $\begin{array}{l}\text { Precis } \\
\text { ion }\end{array}$ & $\begin{array}{l}\text { Sensiti } \\
\text { vity }\end{array}$ & $\begin{array}{l}\text { F1- } \\
\text { score }\end{array}$ & $\begin{array}{l}\mathrm{M} \\
\mathrm{CC}\end{array}$ & $\begin{array}{c}\text { Supp } \\
\text { ort }\end{array}$ \\
\hline \multirow{8}{*}{ RF } & \multirow{2}{*}{$\begin{array}{l}\text { Erodibility } \\
\text { cluster }\end{array}$} & \begin{tabular}{|l|} 
PBM \\
(Python)
\end{tabular} & 79.22 & 0.788 & 0.783 & 0.782 & 0.782 & $\begin{array}{l}0.7 \\
65\end{array}$ & 1098 \\
\hline & & \begin{tabular}{|l} 
SPBM \\
(WEKA)
\end{tabular} & 48.91 & 0.425 & .418 & 0.412 & 0.415 & $\begin{array}{l}0.3 \\
97\end{array}$ & 1098 \\
\hline & \multirow{2}{*}{$\begin{array}{l}\text { Erosivity } \\
\text { cluster }\end{array}$} & $\begin{array}{l}\text { PBM } \\
\text { (Python) }\end{array}$ & 79.10 & 0.789 & 0.781 & 0.780 & 0.780 & $\begin{array}{l}0.6 \\
98\end{array}$ & 1098 \\
\hline & & $\begin{array}{l}\text { SPBM } \\
\text { (WEKA) }\end{array}$ & 44.21 & 0.438 & 0.426 & 0.411 & 0.418 & $\begin{array}{l}0.4 \\
05\end{array}$ & 1098 \\
\hline & \multirow{2}{*}{$\begin{array}{l}\text { Resistance } \\
\text { cluster }\end{array}$} & \begin{tabular}{|l|} 
PBM \\
(Python)
\end{tabular} & 78.96 & 0.784 & .771 & 0.771 & 0.771 & $\begin{array}{l}0.7 \\
65\end{array}$ & 1098 \\
\hline & & $\begin{array}{l}\text { SPBM } \\
\text { (WEKA) }\end{array}$ & 43.42 & 0.429 & .424 & 0.417 & 0.420 & $\begin{array}{l}0.4 \\
08\end{array}$ & 1098 \\
\hline & \multirow{2}{*}{$\begin{array}{l}\text { Topographica } \\
1 \text { cluster }\end{array}$} & $\begin{array}{l}\text { PBM } \\
\text { (Python) }\end{array}$ & 76.89 & 0.756 & 0.751 & 0.748 & 0.749 & $\begin{array}{l}0.7 \\
34\end{array}$ & 1098 \\
\hline & & $\begin{array}{l}\text { SPBM } \\
\text { (WEKA) }\end{array}$ & 41.32 & 0.409 & .398 & 0.391 & 0.394 & $\begin{array}{l}0.3 \\
81\end{array}$ & 1098 \\
\hline \multirow{3}{*}{$\begin{array}{l}\mathrm{AD} \\
\mathrm{B}\end{array}$} & \multirow{2}{*}{$\begin{array}{l}\text { Erodibility } \\
\text { cluster }\end{array}$} & $\begin{array}{l}\text { PBM } \\
\text { (Python) }\end{array}$ & 77.10 & 0.775 & 0.778 & 0.765 & 0.771 & $\begin{array}{l}0.7 \\
58 \\
\end{array}$ & 1098 \\
\hline & & $\begin{array}{l}\text { SPBM } \\
\text { (WEKA) }\end{array}$ & 35.76 & 0.344 & 0.335 & 0.331 & 0.333 & $\begin{array}{l}0.3 \\
28 \\
28\end{array}$ & 1098 \\
\hline & $\begin{array}{l}\text { Erosivity } \\
\text { cluster }\end{array}$ & $\begin{array}{l}\text { PBM } \\
\text { (Python) }\end{array}$ & 76.33 & 0.758 & 0.754 & 0.751 & 0.752 & $\begin{array}{l}0.7 \\
40\end{array}$ & 1098 \\
\hline
\end{tabular}




\begin{tabular}{|c|c|c|c|c|c|c|c|c|c|}
\hline & & $\begin{array}{l}\text { SPBM } \\
\text { (WEKA) }\end{array}$ & 32.57 & 0.318 & 0.311 & 0.310 & 0.310 & $\begin{array}{l}0.2 \\
97\end{array}$ & 1098 \\
\hline & \multirow{2}{*}{$\begin{array}{l}\text { Resistance } \\
\text { cluster }\end{array}$} & $\begin{array}{l}\text { PBM } \\
\text { (Python) }\end{array}$ & 75.40 & 0.745 & 0.736 & 0.731 & 0.733 & $\begin{array}{l}0.7 \\
18\end{array}$ & 1098 \\
\hline & & $\begin{array}{l}\text { SPBM } \\
\text { (WEKA) }\end{array}$ & 31.63 & 0.306 & 0.299 & 0.297 & 0.298 & $\begin{array}{l}0.2 \\
87\end{array}$ & 1098 \\
\hline & \multirow{2}{*}{$\begin{array}{l}\text { Topographica } \\
1 \text { cluster }\end{array}$} & $\begin{array}{l}\text { PBM } \\
\text { (Python) }\end{array}$ & 72.80 & 0.709 & 0.695 & 0.690 & 0.692 & $\begin{array}{l}0.6 \\
63\end{array}$ & 1098 \\
\hline & & $\begin{array}{l}\text { SPBM } \\
\text { (WEKA) }\end{array}$ & 30.10 & 0.296 & 0.291 & 0.287 & 0.289 & $\begin{array}{l}0.2 \\
75\end{array}$ & 1098 \\
\hline \multirow{8}{*}{$\begin{array}{l}\text { SV } \\
\mathrm{M}\end{array}$} & \multirow{2}{*}{$\begin{array}{l}\text { Erodibility } \\
\text { cluster }\end{array}$} & $\begin{array}{l}\text { PBM } \\
\text { (Python) }\end{array}$ & 75.18 & 0.745 & 0.731 & 0.727 & 0.729 & $\begin{array}{l}0.7 \\
21\end{array}$ & 1098 \\
\hline & & $\begin{array}{l}\text { SPBM } \\
\text { (WEKA) }\end{array}$ & 44.57 & 0.431 & 0.425 & 0.432 & 0.428 & $\begin{array}{l}0.4 \\
26\end{array}$ & 1098 \\
\hline & \multirow{2}{*}{$\begin{array}{l}\text { Erosivity } \\
\text { cluster }\end{array}$} & $\begin{array}{l}\text { PBM } \\
\text { (Python) }\end{array}$ & 74.89 & 0.748 & 0.736 & 0.731 & 0.733 & $\begin{array}{l}0.7 \\
29\end{array}$ & 1098 \\
\hline & & $\begin{array}{l}\text { SPBM } \\
\text { (WEKA) }\end{array}$ & 42.15 & 0.410 & 0.398 & 0.391 & 0.394 & $\begin{array}{l}0.3 \\
87\end{array}$ & 1098 \\
\hline & \multirow{2}{*}{$\begin{array}{l}\text { Resistance } \\
\text { cluster }\end{array}$} & $\begin{array}{l}\text { PBM } \\
\text { (Python) }\end{array}$ & 73.11 & 0.721 & 0.723 & 0.718 & 0.720 & $\begin{array}{l}0.7 \\
12\end{array}$ & 1098 \\
\hline & & $\begin{array}{l}\text { SPBM } \\
\text { (WEKA) }\end{array}$ & 41.51 & 0.397 & 0.388 & 0.381 & 0.384 & $\begin{array}{l}0.3 \\
69\end{array}$ & 1098 \\
\hline & \multirow{2}{*}{$\begin{array}{l}\text { Topographica } \\
1 \text { cluster }\end{array}$} & $\begin{array}{l}\text { PBM } \\
\text { (Python) }\end{array}$ & 71.98 & 0.719 & 0.711 & 0.700 & 0.705 & $\begin{array}{l}0.6 \\
84\end{array}$ & 1098 \\
\hline & & $\begin{array}{l}\text { SPBM } \\
\text { (WEKA) }\end{array}$ & 39.47 & 0.374 & 0.368 & 0.361 & 0.364 & $\begin{array}{l}0.3 \\
50\end{array}$ & 1098 \\
\hline
\end{tabular}

\section{Discussion}

The study exhibited that about $20 \%$ area at the upper part of the study area is very highly susceptible to gully erosion. The predictability of the RF model is the most credible since its agreement between training and the testing dataset is very high. The predictability of pixel based models is far better than sample point based models. Now the question is why a higher degree of gully erosion susceptibility is found at the upper part of the study region? Why predictability of pixel based models is higher than sample size based models. May sample size be an issue of improving the accuracy of the models?

The upper reach of every river basin is characterized by higher $1^{\text {st }}$ and $2^{\text {nd }}$ order stream frequency and density and is prone to gully erosion with different intensities (Das, 2014). New gully formation and extension of the gully are very general mechanisms in such an area. But a river basin where highly erodible coarse texture soil is available, such rate is found very high. In the 
Mayurakshi river basin, the lateritic composition of soil enriched with silica, aluminium, iron etc. is highly prone to chemical weathering and consequent erosion (Ghosh et al., 2015). Field study also revealed the fact that gully formation and extension is also very prominent even in the forested lateritic region. In the region where hard lateritic duricrust is there, the rate of gully erosion is quite less. In the present case study, a few lateritic patches are there where hard cap lateritic mass is armoured the fragile laterite soil. Poor undergrowth of vegetation in the sal (Shorea robusta) forest available in a wider part of the upper catchment also insists intensive gully erosion. The growing rate of stone collection from the hilly region, growth of settlement with the forested region, illegal deforestation all are responsible for creating an ambient condition of highly intensive soil erosion. For this, some forested regions and their peripheral part are also prone to high gully erosion susceptibility. Higher drainage frequency and drainage density in its upper part coupling with relatively steeper slope and fragile laterite soil strongly control the gully erosion. Pal and Debanshi (2018) also condemned the fragility of laterite soil as a dominant factor for the high rate of gully erosion in this area.

Pixel based modelling in Python software provided more accurate results than sample point based modelling in this study. It is because there is no need for interpolation while every pixel was considered for analysis. So, here total pixel is the total sample points. But in case of sample point based modelling, based on known values of the training sites unknown sites were predicted using the interpolation method. Interpolation often generalizes the trend of value gradient. It may not always represent reality properly (Abdulmanov et al., 2021). During interpolation, several issues are associated with making the map more precise. Sample point size for interpolation is the first and foremost issue that can dictate the precision of the interpolated map. The sample size is indirectly related to the degree of accuracy of the interpolated map (Simpson and $\mathrm{Wu}, 2014$ ). In this study, 3658 sample sites were taken for analysis.

Ensemble machine learning models were applied for predicting gully erosion susceptibility considering its robustness and high precision level. In the present study, all models were found acceptable but precision is high in the case of the RF model. In the RF algorithm there is a builtin features selection system used to reduce dimensionality without removing any data in the database therefore, there is very little chance of data loss or outlier intervention in the dataset which makes this algorithm more reliable and error-free than the other algorithm (Zhou et al., 2020). The 
RF (uses bagging) is more sensitive to noise than the algorithms based on boosting technique therefore, it generates more accurate prediction by controlling the noise in the dataset (Chan and Paelinckx, 2008; Pal and Mather, 2003). The multi-model approach was adopted here to enhance the reliability of comparison. Multiple models in the same aim cross-validate themselves and therefore, are more reliable in the modelling approach (Arabameri et al., 2020). Moreover, such an approach helps to justify the best representative model among all. Considering these advantages, in recent time so many scholars like Kadavi et al., (2018); Mosavi et al., (2018); Hong et al., (2018); Liu et al., (2018); Jamali, (2019) have taken this line of thinking.

For checking gully erosion in this region theoretically, there may be some ways, however, checking damming is an effective measure. For this since the last seven decades, this engineering mechanism has been highly relied on. Small scale check damming can break down the slope and store the regional soil. A good number of check dams were installed in the catchment of the Massanjore dam over the Mayurakshi river to check soil erosion and thereby lengthen the longevity of the dam (Pal, 2016, Pal and Debanshi, 2020). So, this could be a good way. Renovation of existing dams and installation of a new dam in the deserving sites may check the rate of soil erosion. For finding out the deserving sites for new check dam sites, further research is necessary for this line. As far as the soil type is concerned it is quite difficult to arrest such erosion but check damming may slow down such rate.

The present study has compared the pixel and point based ensemble ML models for gully erosion susceptibility. This approach is very new and the finding of this may encourage scholars to do with such software environment like Python where every pixel to be a sample. It also proved that sample point based modelling which is done frequently is with considerable noise and such output may mislead spatial planning. It is further to be mentioned that here only the output of particular sample size was generated, if instead of this the same modelling process was run using different sample sizes and accuracy was assessed, the result was more easily convincing. So the analysis of sample size effect on model output is a good scope of work.

\section{Conclusion}

The present study inferred that the predictability of pixel based ensemble models is higher than sample point based models. RF model shows the highest precision for predicting gully erosion 
susceptibility both in the case of pixel and point based modelling. Coarser laterite soil dominated fertile soil in the upper part of the study region is more susceptible than its counterparts. So, the study recommends using pixel based ensemble modelling for predicting susceptibility instead of sample point based modelling. The conventional practice of modelling with sample point data using interpolation technique generalizes the spatial character and thereby reduces the precision of the model. An increase of undergrowth and check damming may be some fruitful measures to slow down the gully erosion rate. Since the study demonstrated the gully erosion susceptible region, this information will be useful to the decision-makers for protecting gully erosion and soil resources.

\section{References}

Abdulmanov, R., Miftakhov, I., Ishbulatov, M., Galeev, E., \& Shafeeva, E. (2021). Comparison of the effectiveness of GIS-based interpolation methods for estimating the spatial distribution of agrochemical soil properties. Environmental Technology \& Innovation, 24, 101970.

Acortes, C., \& Vapnik, V. (1995). Support vector networks. Machine Learning. Machine Learning, 20(1), 273-297.

Arabameri, A., Chandra Pal, S., Costache, R., Saha, A., Rezaie, F., Seyed Danesh, A., ... \& Hoang, N. D. (2021). Prediction of gully erosion susceptibility mapping using novel ensemble machine learning algorithms. Geomatics, Natural Hazards and Risk, 12(1), 469-498.

Arabameri, A., Chen, W., Loche, M., Zhao, X., Li, Y., Lombardo, L., ... \& Bui, D. T. (2020). Comparison of machine learning models for gully erosion susceptibility mapping. Geoscience Frontiers, 11(5), 1609-1620.

Arabameri, A., Pradhan, B., Pourghasemi, H. R., Rezaei, K., \& Kerle, N. (2018). Spatial modelling of gully erosion using GIS and R programing: A comparison among three data mining algorithms. Applied sciences, 8(8), 1369.

Asif, M., Nishat, M. M., Faisal, F., Dip, R. R., Udoy, M. H., Shikder, M., \& Ahsan, R. (2021). Performance Evaluation and Comparative Analysis of Different Machine Learning Algorithms in Predicting Cardiovascular Disease. Engineering Letters, 29(2).

Auchincloss, A. H., Gebreab, S. Y., Mair, C., \& Diez Roux, A. V. (2012). A review of spatial methods in epidemiology, 2000-2010. Annual review of public health, 33, 107-122. 
Bandyopadhyay, S., Kar, N. S., Das, S., \& Sen, J. (2014). River systems and water resources of West Bengal: a review. Geological Society of India Special Publication, 3(2014), 63-84.

Brownlee, J. (2016). Machine learning mastery with python. Machine Learning Mastery Pty Ltd, 527, 100-120.

Brownlee, J. (2019). Machine learning mastery with Weka. Ebook. Edition, 1, p.4.

Can, R., Kocaman, S., \& Gokceoglu, C. (2021). A Comprehensive Assessment of XGBoost Algorithm for Landslide Susceptibility Mapping in the Upper Basin of Ataturk Dam, Turkey. Applied Sciences, 11(11), 4993.

Cánovas, J. B., Stoffel, M., Martín-Duque, J. F., Corona, C., Lucía, A., Bodoque, J. M., \& Montgomery, D. R. (2017). Gully evolution and geomorphic adjustments of badlands to reforestation. Scientific reports, 7(1), 1-8.

Chabuk, A., Al-Madhlom, Q., Al-Maliki, A., Al-Ansari, N., Hussain, H. M., \& Laue, J. (2020). Water quality assessment along Tigris River (Iraq) using water quality index (WQI) and GIS software. Arabian Journal of Geosciences, 13(14), 1-23.

Chan, J. C. W., \& Paelinckx, D. (2008). Evaluation of Random Forest and Adaboost tree-based ensemble classification and spectral band selection for ecotope mapping using airborne hyperspectral imagery. Remote Sensing of Environment, 112(6), 2999-3011.

Chicco, D., \& Jurman, G. (2020). The advantages of the Matthews correlation coefficient (MCC) over F1 score and accuracy in binary classification evaluation. BMC genomics, 21(1), 1-13.

Chicco, D., Tötsch, N., \& Jurman, G. (2021). The Matthews correlation coefficient (MCC) is more reliable than balanced accuracy, bookmaker informedness, and markedness in two-class confusion matrix evaluation. BioData mining, 14(1), 1-22.

Churpek, M. M., Yuen, T. C., Winslow, C., Meltzer, D. O., Kattan, M. W., \& Edelson, D. P. (2016). Multicenter comparison of machine learning methods and conventional regression for predicting clinical deterioration on the wards. Critical care medicine, 44(2), 368.

Das, D. (2014). Identification of erosion prone areas by morphometric analysis using GIS. Journal of the Institution of Engineers (india): Series A, 95(1), 61-74.

Debanshi, S., \& Pal, S. (2020). Assessing gully erosion susceptibility in Mayurakshi river basin of eastern India. Environment, Development and Sustainability, 22(2), 883-914. 
Deiss, L., Margenot, A. J., Culman, S. W., \& Demyan, M. S. (2020). Tuning support vector machines regression models improves prediction accuracy of soil properties in MIR spectroscopy. Geoderma, 365, 114227.

Dutta, S. (2016). Soil erosion, sediment yield and sedimentation of reservoir: a review. Modeling Earth Systems and Environment, 2(3), 1-18.

Eibe, F., Hall, M. A., \& Witten, I. H. (2016). The WEKA workbench. Online appendix for data mining: practical machine learning tools and techniques. In Morgan Kaufmann.

Elavarasan, D., \& Vincent, P. D. R. (2021). A reinforced random forest model for enhanced crop yield prediction by integrating agrarian parameters. Journal of Ambient Intelligence and Humanized Computing, 1-14.

Frey, U. (2020). Putting machine learning to use in natural resource management-improving model performance. Ecology and Society, 25(4).

Ghosh, S., Guchhait, S. K., \& Hu, X. F. (2015). Characterization and evolution of primary and secondary laterites in northwestern Bengal Basin, West Bengal, India. Journal of Palaeogeography, 4(2), 203-230.

González, S., García, S., Del Ser, J., Rokach, L., \& Herrera, F. (2020). A practical tutorial on bagging and boosting based ensembles for machine learning: Algorithms, software tools, performance study, practical perspectives and opportunities. Information Fusion, 64, 205-237.

Han, X., Lv, P., Zhao, S., Sun, Y., Yan, S., Wang, M., ... \& Wang, X. (2018). The Effect of the Gully Land consolidation project on soil erosion and crop production on a typical watershed in the loess plateau. Land, 7(4), 113.

Hartini, S., Rustam, Z., Saragih, G. S., \& Vargas, M. J. S. (2021). Estimating probability of banking crises using random forest. IAES International Journal of Artificial Intelligence, 10(2), 407.

He, H., Khoshelham, K., \& Fraser, C. (2020). A multiclass TrAdaBoost transfer learning algorithm for the classification of mobile lidar data. ISPRS Journal of Photogrammetry and Remote Sensing, 166, 118-127.

Hoeser, T., \& Kuenzer, C. (2020). Object detection and image segmentation with deep learning on earth observation data: A review-part i: Evolution and recent trends. Remote Sensing, 12(10), 1667. 
Hoeser, T., Bachofer, F., \& Kuenzer, C. (2020a). Object detection and image segmentation with deep learning on Earth observation data: A review_Part II: Applications. Remote Sensing, 12(18), 3053.

Hogland, J. S., \& Anderson, N. M. (2014). Improved analyses using function datasets and statistical modeling. In In: Proceedings of the 2014 ESRI Users Conference; July 14-18, 2014, San Diego, CA. Redlands, CA: Environmental Systems Research Institute. Online: http://proceedings. esri. com/library/userconf/proc14/papers/166_182. pdf. (pp. 166-182).

Hogland, J. S., \& Anderson, N. M. (2015). Estimating FIA plot characteristics using NAIP imagery, function modeling, and the RMRS Raster Utility coding library. In In: Stanton, Sharon M.; Christensen, Glenn A., comps. 2015. Pushing boundaries: new directions in inventory techniques and applications: Forest Inventory and Analysis (FIA) symposium 2015. 2015 December 8-10; Portland, Oregon. Gen. Tech. Rep. PNW-GTR-931. Portland, OR: US Department of Agriculture, Forest Service, Pacific Northwest Research Station: 340-344. (Vol. 931, pp. 340-344).

Hogland, J., \& Anderson, N. (2017). Function modeling improves the efficiency of spatial modeling using big data from remote sensing. Big Data and Cognitive Computing, 1(1), 3.

Hong, H., Liu, J., Bui, D. T., Pradhan, B., Acharya, T. D., Pham, B. T., ... \& Ahmad, B. B. (2018). Landslide susceptibility mapping using J48 Decision Tree with AdaBoost, Bagging and Rotation Forest ensembles in the Guangchang area (China). Catena, 163, 399-413.

Hosseinalizadeh, M., Kariminejad, N., Chen, W., Pourghasemi, H. R., Alinejad, M., Behbahani, A. M., \& Tiefenbacher, J. P. (2019). Spatial modelling of gully headcuts using UAV data and four best-first decision classifier ensembles (BFTree, Bag-BFTree, RS-BFTree, and RFBFTree). Geomorphology, 329, 184-193.

Hosseinalizadeh, M., Kariminejad, N., Chen, W., Pourghasemi, H. R., Alinejad, M., Behbahani, A. M., \& Tiefenbacher, J. P. (2019). Gully headcut susceptibility modeling using functional trees, naïve Bayes tree, and random forest models. Geoderma, 342, 1-11.

Jamali, A. (2019). Evaluation and comparison of eight machine learning models in land use/land cover mapping using Landsat 8 OLI: a case study of the northern region of Iran. SN Applied Sciences, 1(11), 1448.

Jha, V. C., \& Kapat, S. (2003). Gully erosion and its implications on land use, a case study. Land degradation and desertification. Publ., Jaipur and New Delhi, 156-178. 
Jha, V. C., \& Kapat, S. (2009). Rill and gully erosion risk of lateritic terrain in South-Western Birbhum District, West Bengal, India. Sociedade \& Natureza, 21, 141-158.

Jung, H. S., \& Lee, S. (Eds.). (2019). Machine Learning Techniques Applied to Geoscience Information System and Remote Sensing. MDPI.

Kadavi, P., Lee, C. W., \& Lee, S. (2018). Application of ensemble-based machine learning models to landslide susceptibility mapping. Remote Sensing, 10(8), 1252.

Kawaguchi, K., Kaelbling, L. P., \& Bengio, Y. (2017). Generalization in deep learning. arXiv preprint arXiv:1710.05468.

Kotthoff, L., Thornton, C., Hoos, H. H., Hutter, F., \& Leyton-Brown, K. (2019). Auto-WEKA: Automatic model selection and hyperparameter optimization in WEKA. In Automated Machine Learning (pp. 81-95). Springer, Cham.

Liu, Y., Yang, Y., Jing, W., \& Yue, X. (2018). Comparison of different machine learning approaches for monthly satellite-based soil moisture downscaling over Northeast China. Remote Sensing, 10(1), 31.

Mansfield, L. A., Nowack, P. J., Kasoar, M., Everitt, R. G., Collins, W. J., \& Voulgarakis, A. (2020). Predicting global patterns of long-term climate change from short-term simulations using machine learning. npj Climate and Atmospheric Science, 3(1), 1-9.

Maxwell, A. E., Bester, M. S., Guillen, L. A., Ramezan, C. A., Carpinello, D. J., Fan, Y., ... \& Pyron, J. L. (2020a). Semantic Segmentation Deep Learning for Extracting Surface Mine Extents from Historic Topographic Maps. Remote Sensing, 12(24), 4145.

Maxwell, A. E., Pourmohammadi, P., \& Poyner, J. D. (2020). Mapping the topographic features of mining-related valley fills using mask R-CNN deep learning and digital elevation data. Remote Sensing, 12(3), 547.

Maxwell, A. E., Warner, T. A., \& Strager, M. P. (2016). Predicting palustrine wetland probability using random forest machine learning and digital elevation data-derived terrain variables. Photogrammetric Engineering \& Remote Sensing, 82(6), 437-447.

Mehmood, Z., \& Asghar, S. (2021). Customizing SVM as a base learner with AdaBoost ensemble to learn from multi-class problems: A hybrid approach AdaBoost-MSVM. Knowledge-Based Systems, 217, 106845. 
Meshram, S. G., Safari, M. J. S., Khosravi, K., \& Meshram, C. (2021). Iterative classifier optimizer-based pace regression and random forest hybrid models for suspended sediment load prediction. Environmental Science and Pollution Research, 28(9), 11637-11649.

Mitrpanont, J., Sawangphol, W., Vithantirawat, T., Paengkaew, S., Suwannasing, P., Daramas, A., \& Chen, Y. C. (2017, November). A study on using Python vs Weka on dialysis data analysis. In 2017 2nd International Conference on Information Technology (INCIT) (pp. 1-6). IEEE.

Mosavi, A., Ozturk, P., \& Chau, K. W. (2018). Flood prediction using machine learning models: Literature review. Water, 10(11), 1536.

Mythili, G., \& Goedecke, J. (2016). Economics of land degradation in India. In Economics of land degradation and improvement-a global assessment for sustainable development (pp. 431-469). Springer, Cham.

Nahkala, B. A., Kaleita, A. L., \& Soupir, M. L. (2021). Empirical tool development for prairie pothole management using AnnAGNPS and random forest. Environmental Modelling \& Software, 105241.

Naudts, J., Mestre, G., \& Hoffman, G. (2004). Improvement of Weka, a datamining tool. Universiteit Gent.

Neyshabur, B., Bhojanapalli, S., McAllester, D., \& Srebro, N. (2017). Exploring generalization in deep learning. arXiv preprint arXiv:1706.08947.

Nishat, M. M., Hasan, T., Nasrullah, S. M., Faisal, F., Asif, M. A. A. R., \& Hoque, M. A. (2021, August). Detection of Parkinson's Disease by Employing Boosting Algorithms. In 2021 Joint 10th International Conference on Informatics, Electronics \& Vision (ICIEV) and 2021 th International Conference on Imaging, Vision \& Pattern Recognition (icIVPR) (pp. 1-7). IEEE.

Nkonya, E., Mirzabaev, A., \& Von Braun, J. (2016). Economics of land degradation and improvement-A global assessment for sustainable development (p. 686). Springer Nature.

Norouzi, H., \& Moghaddam, A. A. (2020). Groundwater quality assessment using random forest method based on groundwater quality indices (case study: Miandoab plain aquifer, NW of Iran). Arabian Journal of Geosciences, 13(18), 1-13.

Oh, H. J., Syifa, M., Lee, C. W., \& Lee, S. (2019). Land subsidence susceptibility mapping using bayesian, functional, and meta-ensemble machine learning models. Applied Sciences, 9(6), 1248. Pal, M., \& Mather, P. M. (2003). An assessment of the effectiveness of decision tree methods for land cover classification. Remote sensing of environment, 86(4), 554-565. 
Pal, S. (2016). Identification of soil erosion vulnerable areas in Chandrabhaga river basin: a multicriteria decision approach. Modeling Earth Systems and Environment, 2(1), 1-11.

Pal, S., \& Debanshi, S. (2018). Influences of soil erosion susceptibility toward overloading vulnerability of the gully head bundhs in Mayurakshi River basin of eastern Chottanagpur Plateau. Environment, Development and Sustainability, 20(4), 1739-1775.

Pal, S., \& Debanshi, S. (2021). Machine learning models for wetland habitat vulnerability in mature Ganges delta. Environmental Science and Pollution Research, 28(15), 19121-19146.

Pal, S., \& Paul, S. (2020). Assessing wetland habitat vulnerability in moribund Ganges delta using bivariate models and machine learning algorithms. Ecological Indicators, 119, 106866.

Pal, S., \& Paul, S. (2021). Linking hydrological security and landscape insecurity in the moribund deltaic wetland of India using tree-based hybrid ensemble method in python. Ecological Informatics, 65, 101422.

Pal, S., Talukdar, S., \& Ghosh, R. (2020). Damming effect on habitat quality of riparian corridor. Ecological Indicators, 114, 106300.

Pham, B. T., Avand, M., Janizadeh, S., Phong, T. V., Al-Ansari, N., Ho, L. S., ... \& Prakash, I. (2020). GIS based hybrid computational approaches for flash flood susceptibility assessment. Water, 12(3), 683.

Pradhan, B., Sameen, M. I., Al-Najjar, H. A., Sheng, D., Alamri, A. M., \& Park, H. J. (2021). A Meta-Learning Approach of Optimisation for Spatial Prediction of Landslides. Remote Sensing, 13(22), 4521.

Rahmati, O., Tahmasebipour, N., Haghizadeh, A., Pourghasemi, H. R., \& Feizizadeh, B. (2017). Evaluation of different machine learning models for predicting and mapping the susceptibility of gully erosion. Geomorphology, 298, 118-137.

Riyadi, S., Mayanti, S., Damarjati, C., \& Puspita, S. (2020, March). Deep Learning for Pixel-based Edge Models Classification of Tertiary Dentine Images. In Proceedings of the 2020 The 3rd International Conference on Information Science and System (pp. 57-60).

Rodriguez-Galiano, V. F., Ghimire, B., Rogan, J., Chica-Olmo, M., \& Rigol-Sanchez, J. P. (2012). An assessment of the effectiveness of a random forest classifier for land-cover classification. ISPRS Journal of Photogrammetry and Remote Sensing, 67, 93-104.

Saha, S., Roy, J., Arabameri, A., Blaschke, T., \& Tien Bui, D. (2020). Machine learning-based gully erosion susceptibility mapping: A case study of Eastern India. Sensors, 20(5), 1313. 
Schonlau, M., \& Zou, R. Y. (2020). The random forest algorithm for statistical learning. The Stata Journal, 20(1), 3-29.

Secretariat, U. N. C. C. D. (2013). A stronger UNCCD for a land-degradation neutral world. Issue Brief, Bonn, Germany, 33.

Simpson, G., \& Wu, Y. H. (2014). Accuracy and effort of interpolation and sampling: can GIS help lower field costs?. ISPRS International Journal of Geo-Information, 3(4), 1317-1333.

Syam, N., \& Kaul, R. (2021). Random Forest, Bagging, and Boosting of Decision Trees. In Machine Learning and Artificial Intelligence in Marketing and Sales. Emerald Publishing Limited.

Talukdar, S., Mankotia, S., Shamimuzzaman, M., \& Mahato, S. (2021). Wetland-inundated area modeling and monitoring using supervised and machine learning classifiers. Advances in Remote Sensing for Natural Resource Monitoring, 346-365.

Tang, W. J., Liu, H. H., \& Liu, B. Y. (2013). Effects of gully erosion and gully filling on soil degradation in the black soil region of Northeast China. Journal of Mountain Science, 10(5), 913922.

Tella, A., Balogun, A. L., Adebisi, N., \& Abdullah, S. (2021). Spatial assessment of PM10 hotspots using Random Forest, K-Nearest Neighbour and Naïve Bayes. Atmospheric Pollution Research, 12(10), 101202.

Tilahun, S. A., Ayana, E. K., Guzman, C. D., Dagnew, D. C., Zegeye, A. D., Tebebu, T. Y., ... \& Steenhuis, T. S. (2016). Revisiting storm runoff processes in the upper Blue Nile basin: The Debre Mawi watershed. Catena, 143, 47-56.

Vörösmarty, G., \& Dobos, I. (2020, October). Green purchasing frameworks considering firm size: a multicollinearity analysis using variance inflation factor. In Supply Chain Forum: An International Journal (Vol. 21, No. 4, pp. 290-301). Taylor \& Francis.

Wang, H., Zhang, L., Yin, K., Luo, H., \& Li, J. (2021). Landslide identification using machine learning. Geoscience Frontiers, 12(1), 351-364.

Wang, Z., Liu, Q., \& Liu, Y. (2020). Mapping landslide susceptibility using machine learning algorithms and GIS: A case study in Shexian County, Anhui Province, China. Symmetry, 12(12), 1954.

Wangchuk, S., \& Bolch, T. (2020). Mapping of glacial lakes using Sentinel-1 and Sentinel-2 data and a random forest classifier: Strengths and challenges. Science of Remote Sensing, 2, 100008. 
Xie, J., Song, Z., Li, Y., Zhang, Y., Yu, H., Zhan, J., ... \& Guo, J. (2018). A survey on machine learning-based mobile big data analysis: Challenges and applications. Wireless Communications and Mobile Computing, 2018.

Xu, Y., Cong, K., Zhu, Q., \& He, Y. (2021). A novel AdaBoost ensemble model based on the reconstruction of local tangent space alignment and its application to multiple faults recognition. Journal of Process Control, 104, 158-167.

Yao, J., \& Shepperd, M. (2020). Assessing software defection prediction performance: Why using the Matthews correlation coefficient matters. In Proceedings of the Evaluation and Assessment in Software Engineering (pp. 120-129).

Zhou, X., Lu, P., Zheng, Z., Tolliver, D., \& Keramati, A. (2020). Accident prediction accuracy assessment for highway-rail grade crossings using random forest algorithm compared with decision tree. Reliability Engineering \& System Safety, 200, 106931.

Zhu, H., Gowen, A., Feng, H., Yu, K., \& Xu, J. L. (2020). Deep Spectral-Spatial Features of Near Infrared Hyperspectral Images for Pixel-Wise Classification of Food Products. Sensors, 20(18), 5322. 


\section{Statements \& Declarations:}

\section{Funding}

The authors declare that no funds, grants, or other support were received during the preparation of this manuscript.

\section{Competing Interests}

The authors have no relevant financial or non-financial interests to disclose.

\section{Author Contributions}

All authors contributed to the study conception and design. Material preparation, data collection and analysis were performed by Swades Pal, Sandipta Debanshi and Satyajit Paul. The first draft of the manuscript was written by Swades Pal and Satyajit Paul and all authors commented on previous versions of the manuscript. All authors read and approved the final manuscript 